\title{
Variability of the Chemical Hydrography at the Frontal Region between the East China Sea and the Kuroshio North-east of Taiwan
}

\author{
George T. F. Wong ${ }^{a}$, Su-Cheng Pai ${ }^{b}$, Kon-Kee Liu ${ }^{b, c}$ \\ Cho-Teng Liu ${ }^{b}$ and Chen-Tung A. Chen ${ }^{d}$ \\ "Department of Oceanography, Old Dominion University, Norfolk, \\ VA 23529-0276, U.S.A., Institute of Oceanography, National Taiwan \\ University, P.O. Box 23-13, Taipei, Taiwan, R.O.C., 'Institute of Earth \\ Science, Academia Sinica, P.O. Box 23-59, Taipei, Taiwan, R.O.C. and \\ "Institute of Marine Geology, National Sun Yat-Sen University, Kaohsiung, \\ Taiwan, R.O.C.
}

Received 1 March 1990 and in revised form 18 February 1991

\begin{abstract}
Keywords: East China Sea; Kuroshio; hydrographic; frontal zone; variation; Taiwan; Okinawa; upwelling

The hydrography across the frontal region between the East China Sea and the Okinawa Trough north-east of Taiwan, observed during the summer of 1985 and 1988 and the early spring of 1987 , was governed mainly by mixing across the front and the topographically induced upwelling of the modified Kuroshio water in the Okinawa Trough during the periodic shelfward migration of the Kuroshio. The location of the front relative to the shelf break seemed to be temporally variable. Topographically induced upwelling was evident during the summer of 1988 and the early spring of 1987 when the front was located close to the shelf break. It might not have occurred in the summer of 1985 when the front was further offshore. The end-member composition of the upwelling water was similar in both seasons. It originated from about $300 \mathrm{~m}$ with a temperature and salinity of $13 \mathrm{C}$ and $34.4 \mathrm{psu}$. It was rich in nutrients and poor in oxygen with concentrations of nitrate, phosphate, silicate and oxygen of $16,1,18$ and $160 \mu \mathrm{M}$ respectively. This upwelling water is potentially a major source of nutrients to the East China Sea. The deep water in the Okinawa Trough at temperatures below $15 \mathrm{Cdid}$ not participate in cross-shelf mixing. Its chemical characteristics did not change significantly from year to year.
\end{abstract}

\section{Introduction}

As the Kuroshio travels from the Equatorial to the North Pacific, it passes through a passage over a ridge between Taiwan and the Yonakunijima and enters the Okinawa Trough. Because of topographic restrictions, this northward-flowing current in the Okinawa Trough has to turn eastward, skirt along the seaward edge of the East China Sea and may interact with this shallow shelf sea before it re-enters the Pacific Ocean south of 
Japan through the Tokara Strait (Figure 1). Extensive studies on the interactions between the Gulf Stream and the South Atlantic Bight (Atkinson, 1985; Atkinson \& Menzel, 1985; Wong, 1988) have demonstrated that material exchange across the frontal region between a western boundary current and the adjacent shelf waters may act as a major control of the biogeochemical processes in the shelf. Conceivably, the Kuroshio may have similar effects on the chemistry in the East China Sea.

The physical characteristics of the frontal zone between the Kuroshio and the East China Sea north-east of Taiwan has been studied for some time (Yin, 1973; Chu, 1976; Fan, 1980; Liu, 1983; Liu \& Pai, 1987; Liu et al., 1989) although data with the appropriate sparial and temporal spacing for studying the exchange processes in the region are still unavailable. Systematic data on the corresponding chemical signatures in the region are sparse (Liu \& Pai, 1987; Liu et al., 1989; Wong et al., 1989). In this paper, we report on a comparison of the chemical hydrography in this region in the spring of 1987 and the summer of 1985 and 1988.

\section{Sampling and analytical methods}

\section{Study area}

The Okinawa Trough is bounded to the north and to the west by the East China Sea which occupies the Tunghai Shelf that extends from the Asian continental mainland to the shelf break at a water depth of about $200 \mathrm{~m}$ (Mogi, 1972). To the south and the east, the Okinawa Trough is bounded by the Okinawa Island chain. Our study area straddles the southern part of the East China Sea and the Okinawa Trough north and north-east of Taiwan where the water depth increases abruptly from 100 to $200 \mathrm{~m}$ at the shelf break and then even more precipitously to over $2 \mathrm{~km}$ at the centre of the Okinawa Trough (Figure 1). The Changjiang, or Yangtze River, empties into the East China Sea and is the major source of freshwater to the study area (Beardsley et al., 1985).

\section{Surveys}

Stations were occupied across the frontal region between the East China Sea and the Kuroshio in the Okinawa Trough north-east of Taiwan during three cruises by R/V Ocean Researcher I: summer 1985 on 12 to 15 September during cruise CHIPS-2 (Cooperative Hydrographic Investigation of the Philippine Sea); spring 1987 on 29 to 31 March during cruise CHIPS-4; and summer 1988 on 19 to 21 September during cruise KECS-2 (Kuroshio-East China Sea Study). The cruise tracks and the locations of the stations are shown in Figure 1.

\section{Methods}

At each station, profiles of temperature and salinity were measured with a Sea-Bird CTD. Discrete samples were collected with Niskin bottles mounted on a rosette sampler for the determination of salinity, dissolved oxygen and phosphate during all three cruises. Nitrate was determined during summer 1985 and summer 1988 while silicate was determined only during summer 1988. Oxygen was measured by the Winkler titrimetric method (Carpenter, 1965). Phosphate was determined by the molybdenum blue method (Murphy \& Riley, 1962). Silicate was measured by the silicomolybdenum blue method (Fanning \& Pilson, 1973). Nitrate was determined by the azo dye method (Strickland \& Parsons, 1972). 


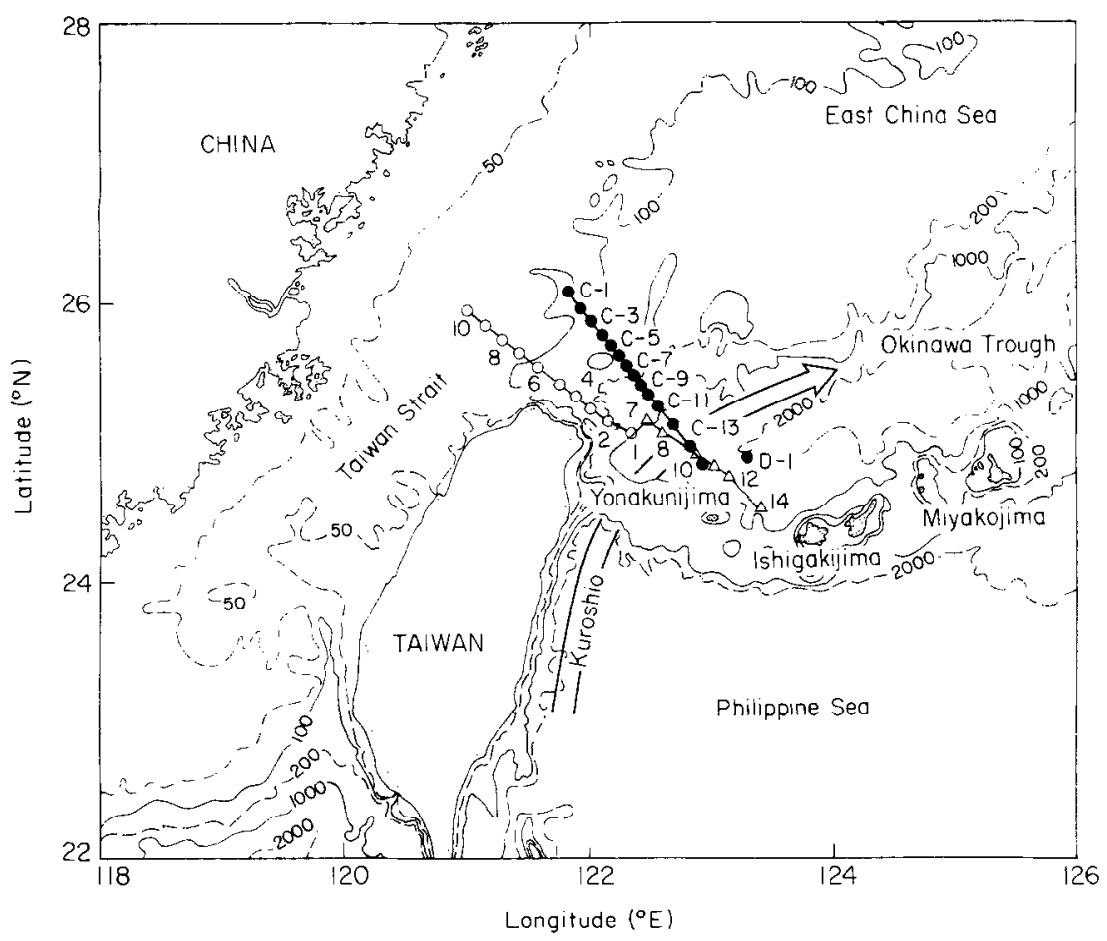

Figure 1. Station locations. $\triangle$, Summer 1985 (CHIPS-2);, spring 1987 (CHIPS-4); $\bullet$, summer 1988 (KECS-2).

\section{Results and discussion}

\section{Temperature-salinity ( $T-S$ ) relationships}

The $\mathrm{T}-\mathrm{S}$ relationships in summer 1988 at selected stations are shown in Figure 2(a). The broad salinity maximum between 34.8 and $34.85 \mathrm{psu}, 19.5$ to $24.5^{\circ} \mathrm{C}$ at 75 to $200 \mathrm{~m}$ at station C-14 and D-1 represented the core of the Kuroshio (Nitani, 1972; Guan, 1983). At shallower depths, the Kuroshio water mixed with the warmer and fresher surface water. The $\mathrm{T}-\mathrm{S}$ curves converged to a common point at about $15^{\circ} \mathrm{C}$ and $34.5 \mathrm{psu}$ with a sigma- $t$ of 28.5 at about 250 to $350 \mathrm{~m}$. Above $15^{\circ} \mathrm{C}$, the T-S curves fanned out systematically from the station farthest offshelf (station D-1) to the station closest inshelf (station C-1). Along each isopycnal, salinity and depth increased from station C-1 to station D-1. However, reversals from this trend were observed occasionally in the intervening stations suggesting that, aside from cross-shelf mixing between shelf water and Kuroshio water along isopycnal surfaccs, upwelling might have occurred resulting in complex mixing processes involving multiple end-members.

Below about $15^{\circ} \mathrm{C}$, temperature was linearly related to salinity down to a broad salinity minimum between 34.3 and $34.35 \mathrm{psu}$, at $7.5^{\circ} \mathrm{C}$ and at 450 to $550 \mathrm{~m}$. This salinity minimum represented the North Pacific Intermediate Water which has been traced from the east of Luzon through the Okinawa Trough to the south-east of Japan (Nitani, 1972; Masuzawa, 1972). The T-S relationships were identical at all stations below $15^{\circ} \mathrm{C}$, indicating that these deeper waters did not participate in the cross-shelf mixing between the East China Sea and the Kuroshio. Its composition was only affected by vertical mixing between Kuroshio water and the North Pacific Intermediate Water. The bottom water in 


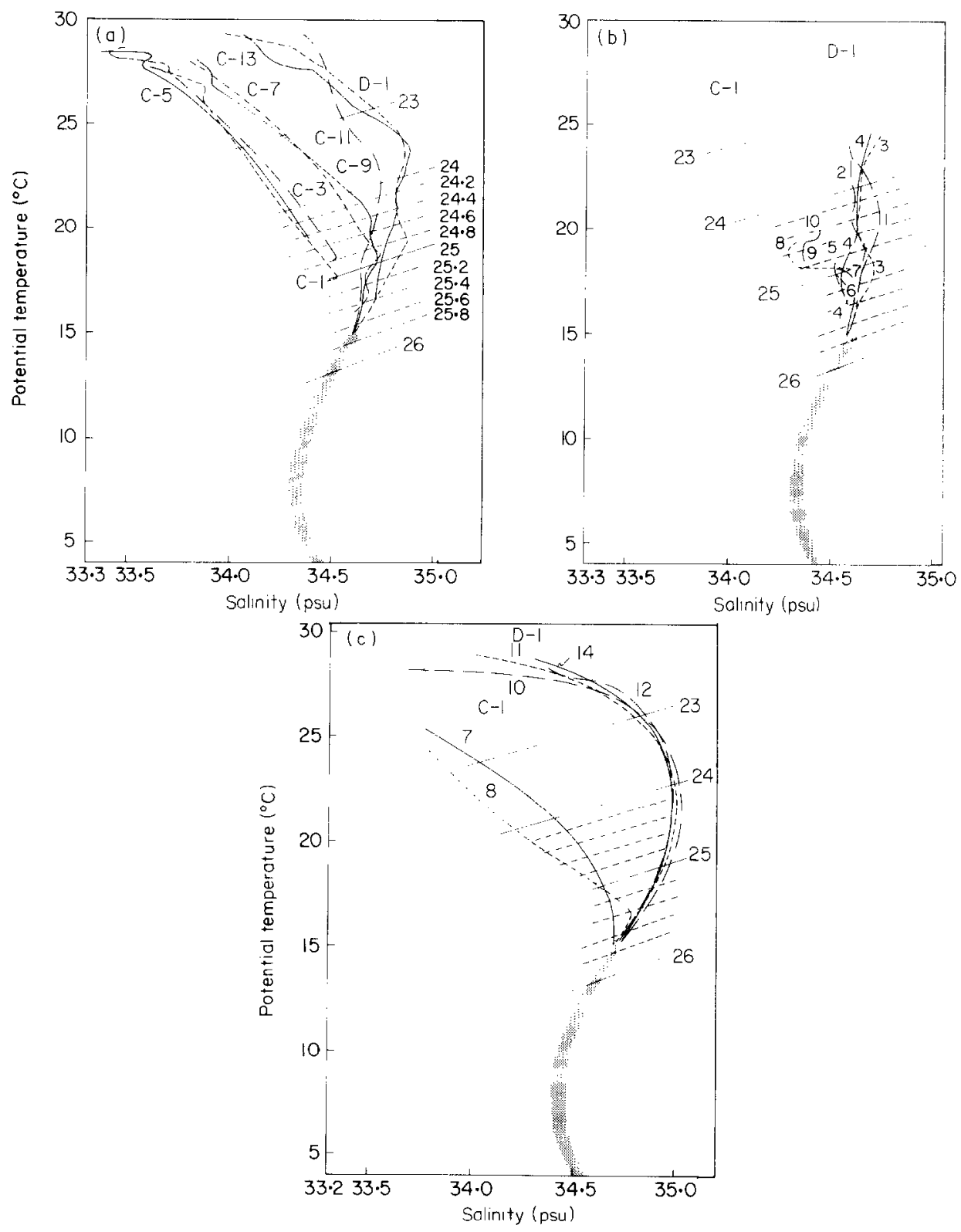

Figure 2. The temperature-salinity relationships ( $\mathrm{T}-\mathrm{S}$ ) at selected stations during (a) summer 1988, (b) spring 1987 and (c) summer 1985. Stippled area indicates the T-S field below $15^{\mathrm{C}} \mathrm{C}$ for all three cruises. Dotted lines in (b) and (c) denote the T-S relationship at stations D-1 and C-1 observed during summer 1988.

the Okinawa Trough was represented as a salinity maximum in the $\mathrm{T}-\mathrm{S}$ curves with temperatures below $5{ }^{\circ} \mathrm{C}$ and salinities above 34.39 psu.

During spring 1987 , above $15^{\circ} \mathrm{C}$, the $\mathrm{T}-\mathrm{S}$ relationships fell into three groups [Figure 2(b)]: at stations 8 to 10,5 to 7 and 1 to 4 . The T-S field of the first, the most inshelf, group of stations was limited to a temperature range of 17 to $20 \mathrm{C}$ and a salinity range of $34 \cdot 25$ to $34.6 \mathrm{psu}$. The coldest surface water was found further offshelf, in the second group of 

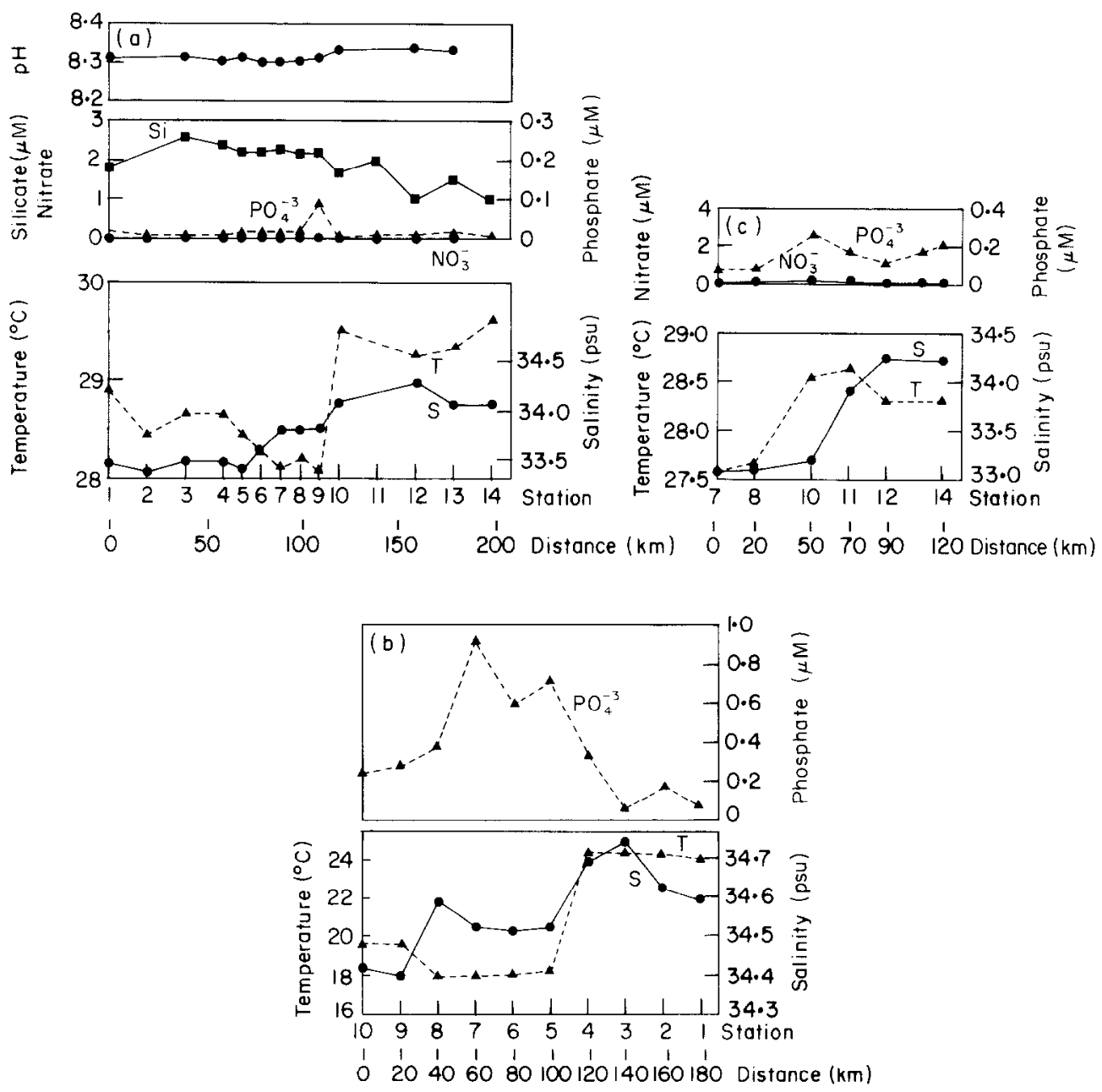

Figure 3. The distribution of temperature (T), salinity (S), phosphate $\left(\mathrm{PO}_{4}^{3}\right)$, nitrate $\left(\mathrm{NO}_{3}\right)$, silicate $(\mathrm{Si})$ and/or $\mathrm{pH}$ in the surface waters along the transect during (a) summer 1988, (b) spring 1987 and (c) summer 1985.

stations where the temperature and salinity ranges were 16 to $18 \cdot 6^{\circ} \mathrm{C}$ and $34 \cdot 5$ to $34.6 \mathrm{psu}$ [Figure 3(b)]. In the third group of stations, the surface temperature reached $24.5 \mathrm{C}$. The $\mathrm{T}-\mathrm{S}$ curves tended to converge together as the temperature decreased. The water depth was great enough only at station 1 to include waters colder than $15 \mathrm{C}$.

In comparison to the data obtained during summer 1988, the temperature field observed during spring 1987 was, as expected, greatly compressed. In the Okinawa Trough, the East China Sea and around the shelf break, the surface water was about 5, 9 and $10^{\circ} \mathrm{C}$ colder respectively [Figure $3(\mathrm{a})$ and (b)]. The shelf water was also more saline. For example, although station 10, occupied during spring 1987, was further inshelf than station C-1, which was occupied during summer 1988, its surface salinity was about $0 \cdot 9$ psu higher [Figure 3(a) and (b)]. This difference in the surface salinity is probably the result of the temporal variation in the discharge of the Changjiang where the peak discharge occurs from late June to August, while the minimum discharge is found in January to March (Beardsley et al., 1985). In the deep waters at temperatures below $15^{\circ} \mathrm{C}$, the 


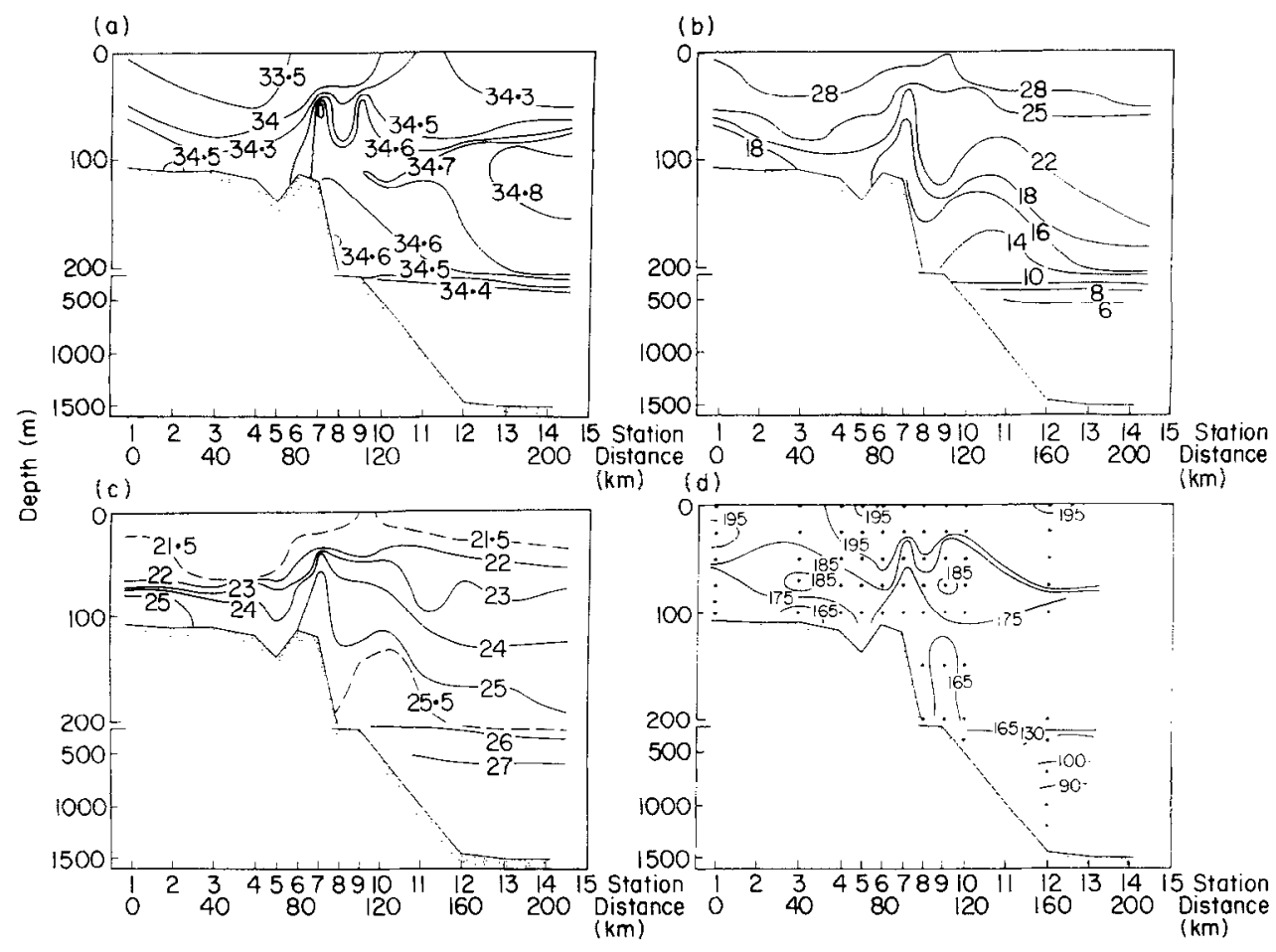

Figure 4. The distribution of (a) salinity (psu) (b) temperature (C), (c) sigma- $t$ and (d) oxygen $(\mu \mathrm{M})$ along the transect during summer 1988 . Locations of discrete samples.

$\mathrm{T}-\mathrm{S}$ relationship was similar to that observed during summer 1988 suggesting that the composition of the deep water was not affected by seasonal events.

During summer 1985 , the $\mathrm{T}-\mathrm{S}$ relationships below $15^{\circ} \mathrm{C}$ were also similar from station to station and to those observed during summer 1988 . Above $15^{\circ} \mathrm{C}$, the $\mathrm{T}-\mathrm{S}$ relationships fell into two groups: stations 7 and 8 , and 10 to 12 and 14 . In the first group of stations, the $\mathrm{T}-\mathrm{S}$ relationship resembled those at the most inshelf stations occupied during summer 1988 even though those stations were about $130 \mathrm{~km}$ further inshelf. In the second group of stations, the $\mathrm{T}-\mathrm{S}$ relationship was similar to those in the Okinawa Trough in summer 1988. The T-S relationship changed abruptly between stations 8 and 10 which were only $30 \mathrm{~km}$ apart. A transition zone between the shelf water and the Kuroshio water in the Okinawa Trough as indicated by the intermediate $\mathrm{T}-\mathrm{S}$ relationships observed during summer 1988 was conspicuously absent. Apparently, during summer 1985, the Kuroshio had moved offshelf enough so that the shelf water extended beyond the shelf break into the Okinawa Trough.

Sections of temperature, salinity and sigma-t

The addition of freshwater to the East China Sea, primarily via the Changjiang, resulted in fresher water on the shelf and more saline water further offshelf. Thus, as a first approximation, the distribution of salinity along the transects resembled that of an estuary (Figures 4-6): a prism of fresher surface water extending offshelf was underlain by the shelfward intrusion of deeper and more saline offshelf waters from the Okinawa Trough, resulting in a salinity front that can be detected as a surface expression (Figures 1 and 3). 


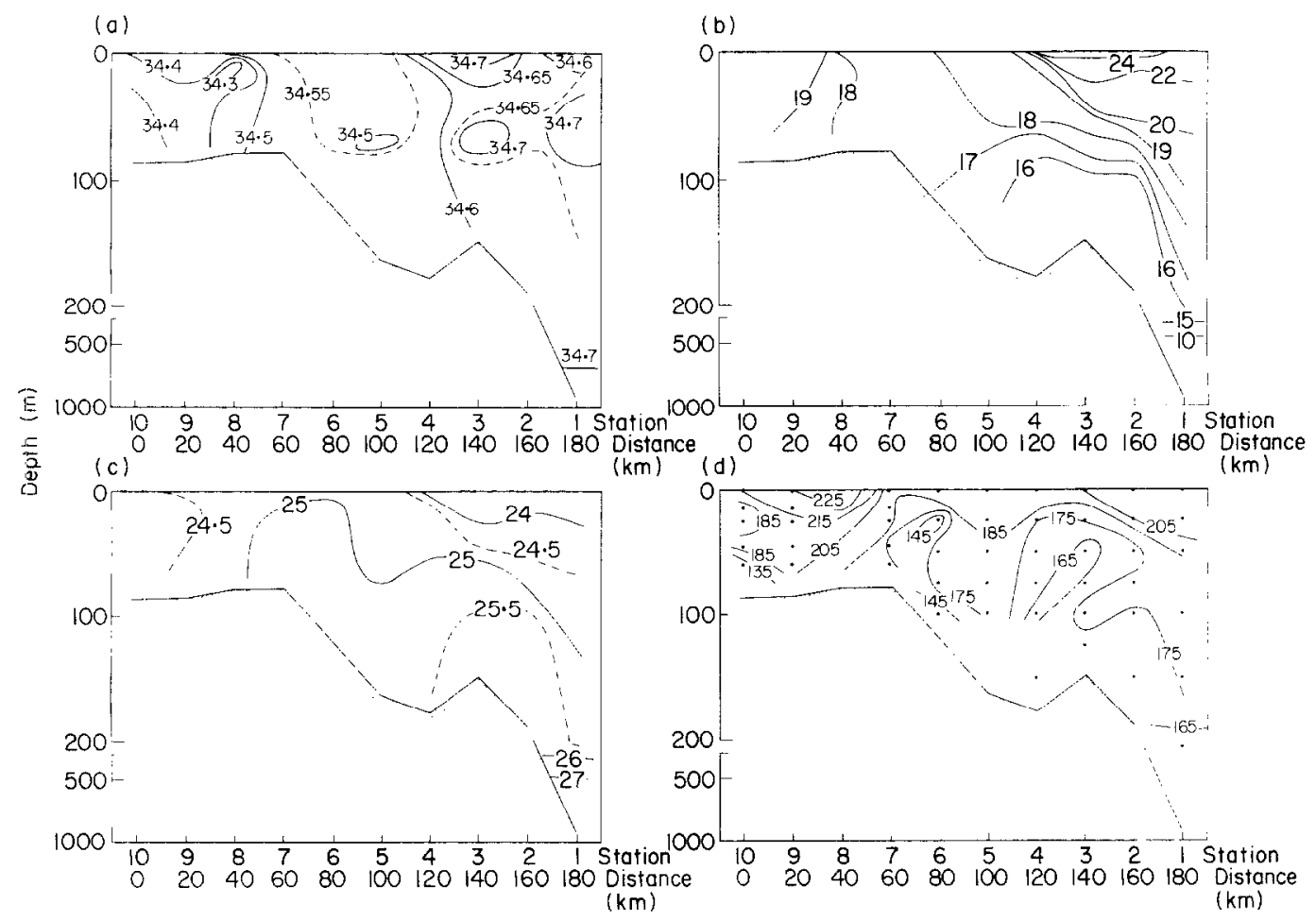

Figure 5. The distribution of (a) salinity (psu) (b) temperature ( C), (c) sigma-t and (d) oxygen $(\mu \mathrm{M})$ along the transect during spring 1987.

Superimposed on this pattern was the influence of the Kuroshio which was represented as a subsurface layer of saline water with a maximum salinity exceeding $34 \cdot 7$ psu and a sigma- $t$ of about 24.5. The interaction between the shelf water and the Kuroshio water varied from one cruise to another. During summer 1988 and spring 1987, topographically induced upwelling at the shelf break was evident as indicated by the shelfward-and upward-tilting isohalines, isotherms and isopycnals which extended over the shelf break Figures 4 and 5). For example, the 34.6-psu isohaline which originated from below the salinity maximum, the 18 " C isotherm and the isopycnal at a sigma- $t$ of 25 climbed by 50 to over $100 \mathrm{~m}$ from the Okinawa Trough to the East China Sea and reached the shelf proper. In contrast, during summer 1985 , the Kuroshio, as depicted by the isohaline at $34.7 \mathrm{psu}$, did not reach the shelf and gave rise to a sharp temperature, salinity and density front between stations 8 and 11 at about $70 \mathrm{~km}$ from the shelf break (Figure 6). No water with a salinity exceeding 34.7 psu was found further inshelf. Evidently, the core of the Kuroshio was situated further offshelf from the shelf break during summer 1985, and, as a result, topographically induced upwelling of Kuroshio water onto the shelf was less intense, if it occurred at all. Thus, while topographically induced upwelling at the shelf break clearly occurred in both summer 1988 and spring 1987, the situation was much less certain in summer 1985. Since the axis of the Kuroshio in this general area has been observed to fluctuate from its mean position by about $40 \mathrm{~km}$ seasonally and inter-annually during the same season (Nitani, 1972), the location of the Kuroshio relative to the shelf break in the study area conceivably may also vary even within a season. Thus, it is unclear whether the observed differences between the two summers reflect inter-annual or intra-seasonal variations. 

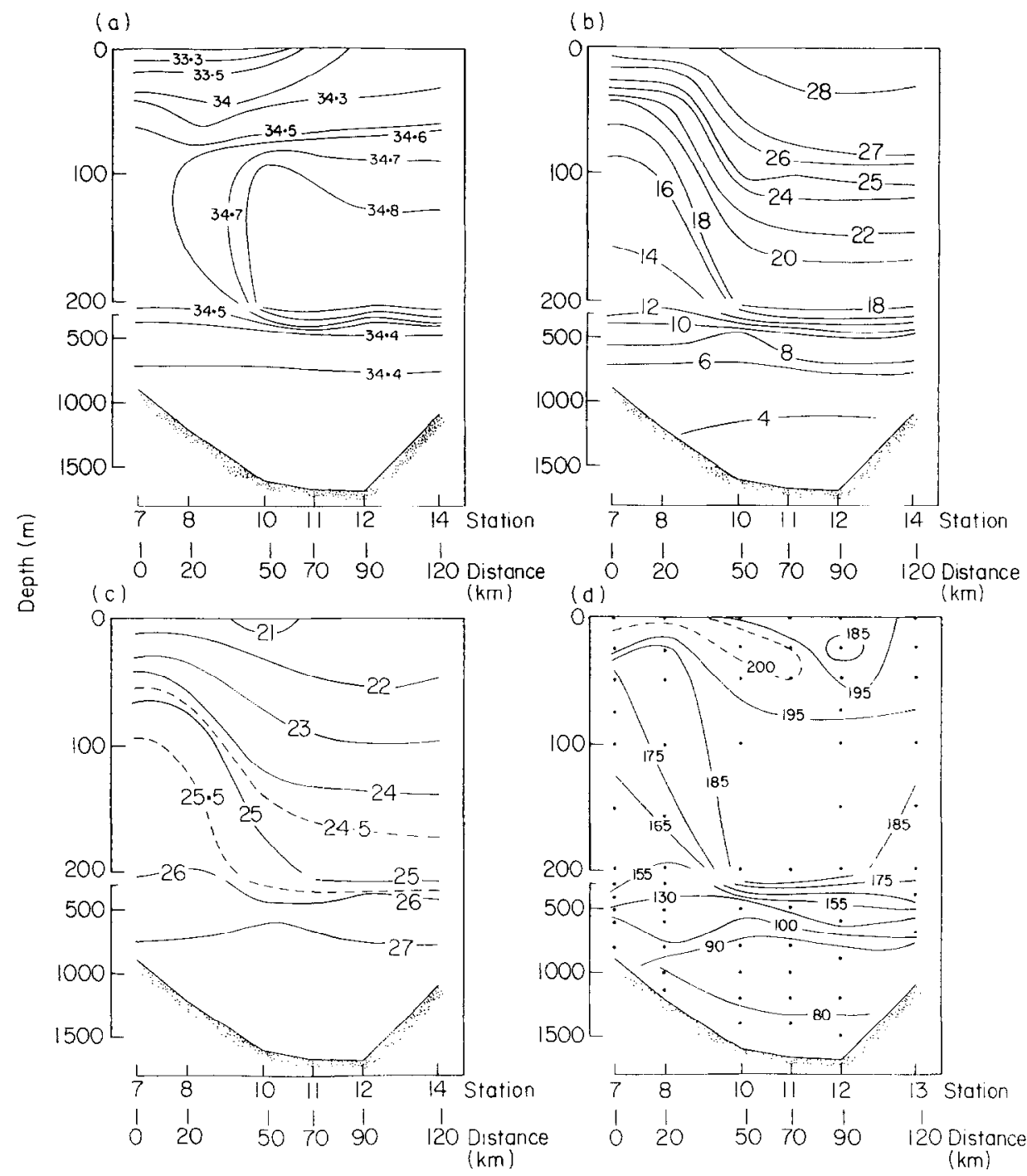

Figure 6. The distribution of (a) salinity, (psu) (b) temperature ( $C$ ), (c) sigma-t and (d) oxygen ( $\mu \mathrm{M}$ ) along the transect during summer 1985 .

The influence of topographically induced upwelling could also be detected as a pool of anomalously cold surface water located at the vicinity of the shelf break [Figure 3(a) and (b)]. Salinity was a less distinct indicator since the salinity of upwelling water was in between those of the waters further inshelf and offshelf (Figures 4 and 5). Although the sigma- $t$ at the core of the Kuroshio was about 24.5 , isopycnals at higher sigma- $t$ and greater depths tilted even more markedly towards shallower depths shelfward. This suggests that the upwelling water was not made up of pure Kuroshio water alone. The influence of the upwelling water on the composition of the shelf water seemed to be more extensive during spring 1987 . Although the isohaline at 34.6 psu could be traced across the Okinawa Trough over the shelf break in both spring 1987 and summer 1988, during summer 1988, the Kuroshio was centred around $110 \mathrm{~m}$ and the shelfward edge of the 


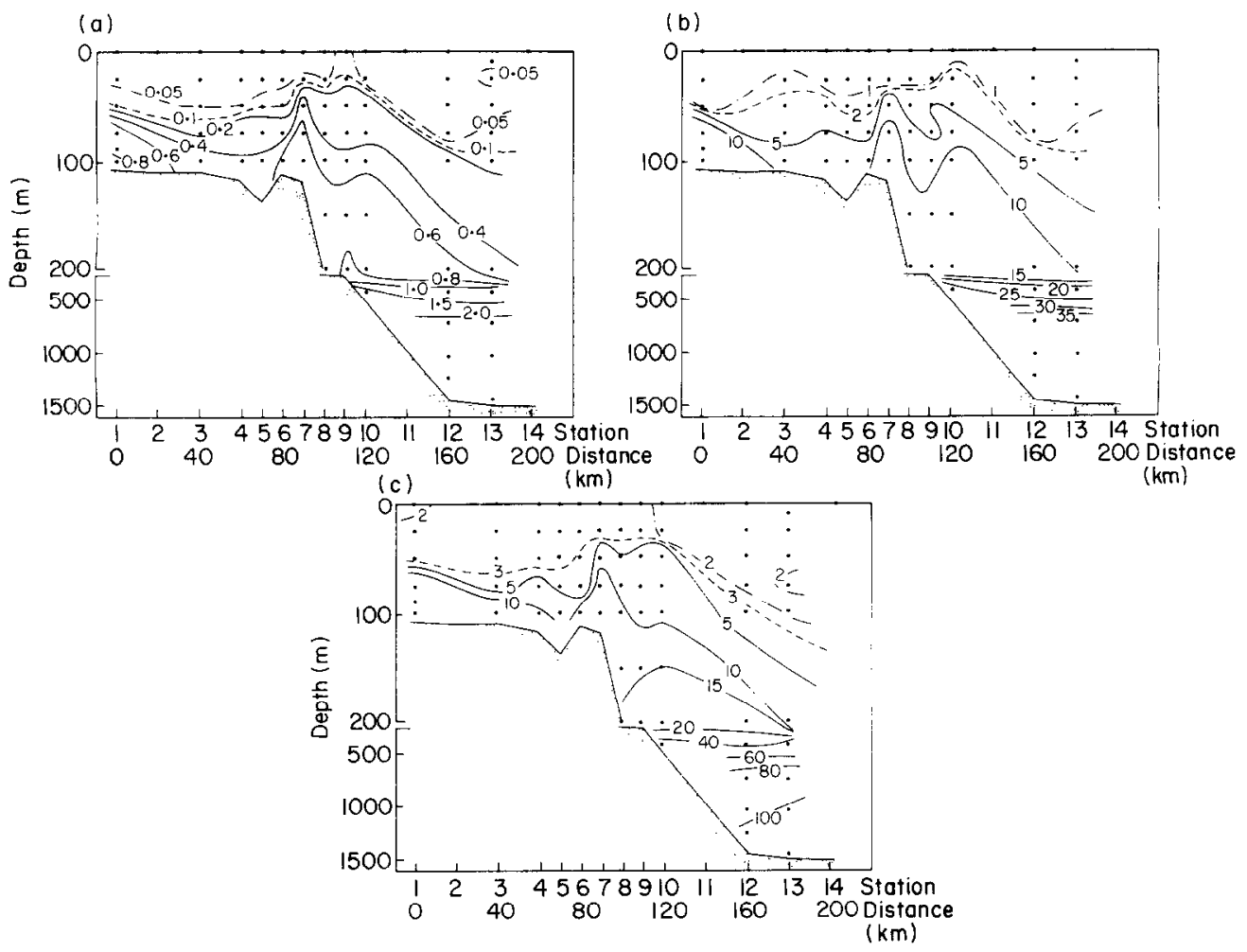

Figure 7. The distribution of (a) phosphate, (b) nitrate and (c) silicate along the transect during summer 1988. All concentrations are $\mu M$.

Kuroshio ended as an abrupt subsurface salinity front at the shelf break. During spring 1987, the core of the Kuroshio was located at a shallower depth at about $50 \mathrm{~m}$ and the 34.5-psu isohaline reached the sea surface.

Some finer-scale hydrographic features were also observed during summer 1988. A prism of bottom water with high salinity, low temperature and a sigma- $t$ exceeding 24.8 was found at the most shelfward stations, $\mathrm{C}-1$ and $\mathrm{C}-2$ (Figure 4). This type of water was found at stations C- 6 to C-14 but was absent in the intervening stations C-3 to C-5, suggesting that another branch of upwelling modified Kuroshio water might have found its way to the most shelfward station in the East China Sea possibly, as an eddy, a filament or as a separate branch of upwelling water. At the shelfward edge of the upwelling water, the isohalines, isotherms and isopycnals formed two bulges between stations C- 6 to C-12 at 50 to $150 \mathrm{~m}$ (Figure 4). Similar structures were also evident during spring 1987 (Figure 5). However, in this case, these structures extended onto the shelf. These bulges, which had dimensions of a few tens of kilometres, may represent eddies or filaments at the shelfward edge of the Kuroshio front or the episodic consecutive inshelf and offshelf meandering of the Kuroshio.

\section{Oxygen, phosphate, nitrate and silicate}

During summer 1988, the topographically induced upwelling at the shelf break, the bulges of this subsurface upwelling water at the vicinity of the shelf break and the occurrence of another parcel of offshelf water at the bottom of stations C-1 to C-3 were also evident from the distribution of oxygen, phosphate, nitrate, and silicate (Figures 4 and 7). 
In the surface waters, the concentrations of phosphate and nitrate were around the detection limit in the entire transect. The concentration of silicate was also low. However, there was an indication that the concentration of silicate in the East China Sea was higher than that in the Okinawa Trough [Figure 3(a)]. This may be a reflection of the influence of the input of river water, water from Changjiang in this case (Edmond et al., 1985), which is well known for its elevated concentrations of silicate relative to surface seawater (Moore et al., 1986), on the chemical composition of the shelf water. The core of the Kuroshio at $110 \mathrm{~m}$ at station C-14 was relatively poor in phosphate, nitrate and silicate with concentrations of $0 \cdot 13,2 \cdot 1$ and $1 \cdot 9 \mu \mathrm{M}$ respectively. The topographically induced upwelling water was characterized by a low concentration of oxygen, between 160 to $175 \mu \mathrm{M}$, and high concentrations of phosphate, nitrate and silicate, between 0.4 and 1,5 and 16, and 5 and $20 \mu \mathrm{M}$ respectively. Thus, while the lateral exchange of Kuroshio water with shelf water would have minimal effect on the nutrient budget, the upwelling water can be an important source of nutrient to the East China Sea. The bottom water at station C-1 was also low in oxygen and high in nutrients.

In the Okinawa Trough, the concentrations of nitrate, phosphate and silicate increased monotonically with depth while that of oxygen decreased in the same fashion. A nutrient maximum or an oxygen minimum zone was not found even at $1400 \mathrm{~m}$ at station C-14 although such features were found routinely at about 800 to $1000 \mathrm{~m}$ in the western Philippine Sea south of the Okinawa Island chain (Yamamoto \& Horikoshi, 1979; Liu et al., 1987a; Pai et al., 1987). This difference in the distributions of oxygen and nutrients suggests that the communication between the oxygen-rich deep water in the western Philippine Sea and the oxygen-poor deep water in the Okinawa Trough may have been severely restricted by the Okinawa Island chain (Liu et al., 1987b). As a result, the in sitt remineralization of organic matter, the concomitant utilization of oxygen within the water column, the diffusive supply of nutrients from the sediments and the removal of oxygen to the sediments in the Okinawa Trough may be large enough to play a prominent role in regulating the composition of the deep and bottom waters in the basin.

During spring 1987, the concentrations of phosphate and oxygen in the surface waters on the shelf at stations 9 and 10 were about $0 \cdot 3$ and $225 \mu \mathrm{M}$ (Figures 5 and 8 ). The corresponding concentrations in the Okinawa Trough at stations 1 to 3 were about $0 \cdot 1$ and $210 \mu \mathrm{M}$. Thus, the composition of these surface waters in terms of phosphate and oxygen were quite similar although their temperature and salinity were obviously different from each other. Between stations 3 and 8 , there was a plume of nutrient-rich and oxygen-poor (up to $24^{\prime \prime}$ ", undersaturated in oxygen at the sea surface), water around the shelf break where the isopleths of the nutrients and oxygen tilted shelfward towards shallower depths. It may represent the transport of water onto the shelf by topographically induced upwelling. The concentrations of phosphate and oxygen in this plume of upwelling water were 0.4 to $>0.8$ and 150 to $200 \mu \mathrm{M}$. Unlike the distributions of nutrients and oxygen observed during summer 1988 , the upwelling water was not confined to below the sea surface. Some of the tilted isopleths reached the sea surface (Figure 8). This difference may result from a stronger upwelling event, a weaker stratification in the water column to impede upwelling and/or a reduced level of biological activity to strip off the nutrients from the upwelling water promptly during this time of the year. Thus, distinct nutrient fronts between the upwelling water and the shelf water and between the upwelling water and the water in the Okinawa Trough were observed at the sea surface [Figure 3(b)] and the concentration of phosphate in the surface waters was substantially higher than those observed during summer 1988. 

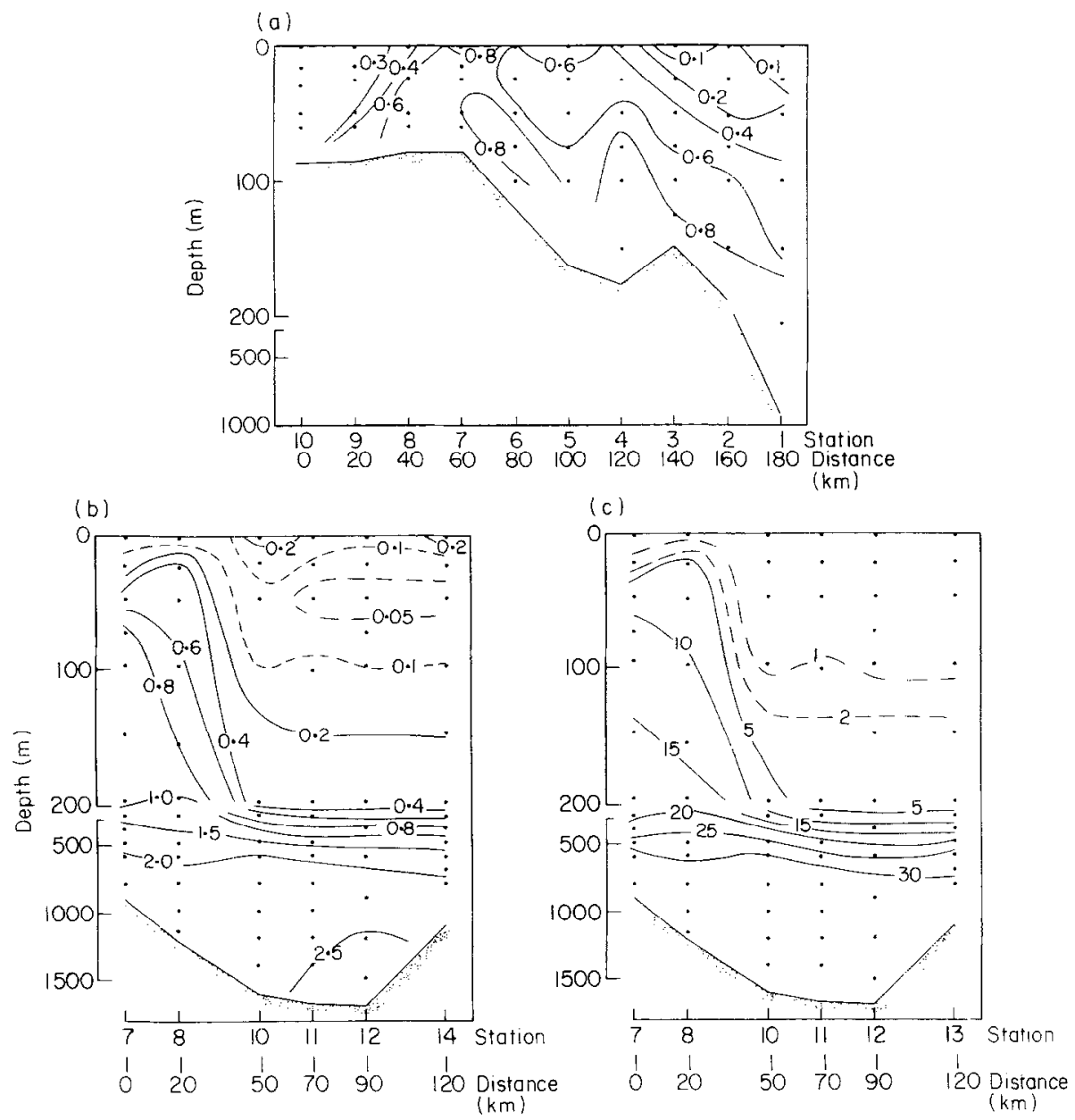

Figure 8. The distribution of (a) phosphate along the transect during spring 1987 and (b) phosphate and (c) nitrate during summer 1985. All concentrations are $\mu \mathrm{M}$.

During summer 1985, there was no distinct nutrient front at the sea surface [Figure $3(c)]$. Both the concentration of nitrate and phosphate hovered around the detection limit in the entire transect. There was only a weak indication of a slightly lower concentration of phosphate at stations 7 and 8 . However, in the subsurface water, there were strong fronts in phosphate, nitrate and oxygen in the top $200 \mathrm{~m}$ between stations 8 and 10 where their concentrations might change by more than an order of magnitude (Figures 6 and 8). Between 30 and $200 \mathrm{~m}$, the concentrations of phosphate, nitrate and oxygen in the inshelf waters were 0.4 to 1,7 to 17 and 146 to $182 \mu \mathrm{M}$ respectively. The corresponding concentrations in the offshelf waters were 0.03 to $0.3,<0.1$ to 5 and 180 to $200 \mu \mathrm{M}$. These distributions are consistent with the notion that the inshelf waters are richer in nutrients relative to the offshelf waters. Howevcr, in the surface waters, during the summer, the biological activity is high enough and the stratification of the water column is strong enough that nutrients can be effectively removed to similar levels in both inshelf and offshelf waters. The concentrations of phosphate, nitrate and oxygen at the centre of the Kuroshio were $0 \cdot 2,3$ and $185 \mu \mathrm{M}$ respectively. These concentrations were similar to those 

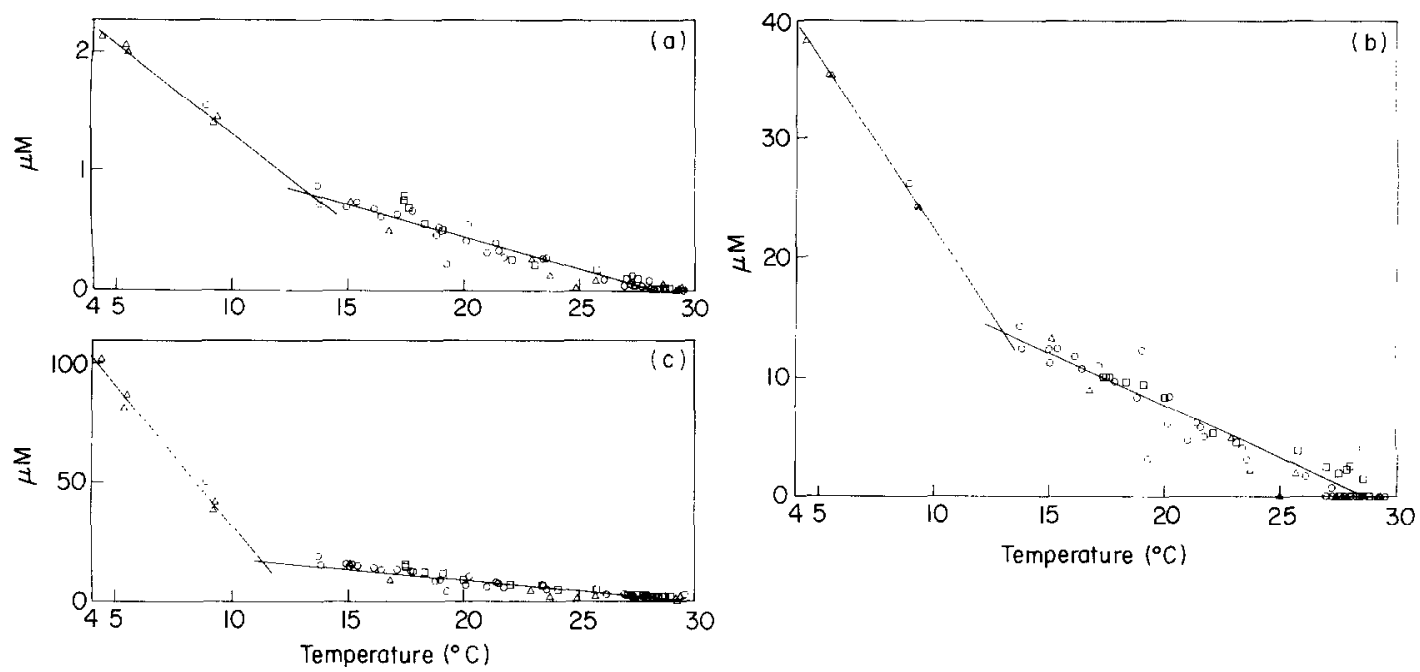

Figure 9. The relationship between (a) phosphate, (b) nitrate, (c) silicate and temperature during summer $1988, \square$, Stations $C-1$ to $C-5 ; 0$, stations $C-6$ to $C-10 ; \Delta$, stations C-11 to $\mathrm{C}-14$.

observed during summer 1988 and spring 1987 indicating that the composition of the Kuroshio did not vary substantially from season to season or from year to year.

\section{Relationships among the chemical hydrographic parameters}

During summer 1988, although there were relatively few data points at temperatures below $15 \mathrm{C}$, the relationship between the concentration of nitrate and temperature seems to fall on two linear lines (Figure 9). The point of intersection of these lines was around 12 to $14^{\circ} \mathrm{C}$, the corresponding depths of which were about 200 to $300 \mathrm{~m}$. Above $13^{\circ} \mathrm{C}$, the relationships were

$$
\begin{array}{ll}
{\left[\mathrm{NO}_{3}\right]=24.9( \pm 0.8)-0.87( \pm 0.03) T} & \text { and } r=-0.96 \\
{\left[\mathrm{PO}_{4}\right]=1.51( \pm 0.04)-0.053( \pm 0.002) T} & \text { and } r=-0.96 \\
{[\mathrm{Si}]=28.5( \pm 1.0)-0.95( \pm 0.04) T} & \text { and } r=-0.95
\end{array}
$$

where $\left[\mathrm{NO}_{3}\right],\left[\mathrm{PO}_{4}\right]$ and $[\mathrm{Si}]$ are the concentrations of nitrate, phosphate and silicate in $\mu \mathrm{M}, T$ is temperature in ${ }^{\circ} \mathrm{C}$ and $r$ is the correlation coefficient. Wong et al. (1989) have examined these data in greater detail by subdividing the stations into three groups according to their proximity to the shelf break: stations 1 to 5 (waters on the shelf), stations 6 to 10 (transition zone) and stations 11 to 14 (Kuroshio waters in the Okinawa Trough). The relationships seemed to change systematically from the shelf to the Okinawa Trough. However, the changes were small, in the order of at most $15^{\circ}{ }_{0}$, in both the slope and the intercept. These linear relationships suggest that one of the dominating processes governing the composition of the water in the top 200 to $300 \mathrm{~m}$ is the mixing of cold, nutrient-rich deeper water with the warm, nutrient-poor surface waters. If these linear relationships can be verified, temperature may be a convenient indicator for estimating exchanges of nutrients between these waters as in the South Atlantic Bight (Dunstan \& Atkinson, 1976; Lee et al., 1981; Atkinson et al., 1982, 1983; Lee \& Atkinson, 1983). Below $13^{\circ} \mathrm{C}$,

$$
\left[\mathrm{NO}_{3}\right]=51.2( \pm 0.7)-2 \cdot 88( \pm 0.09) T \quad \text { and } r=-1.00
$$



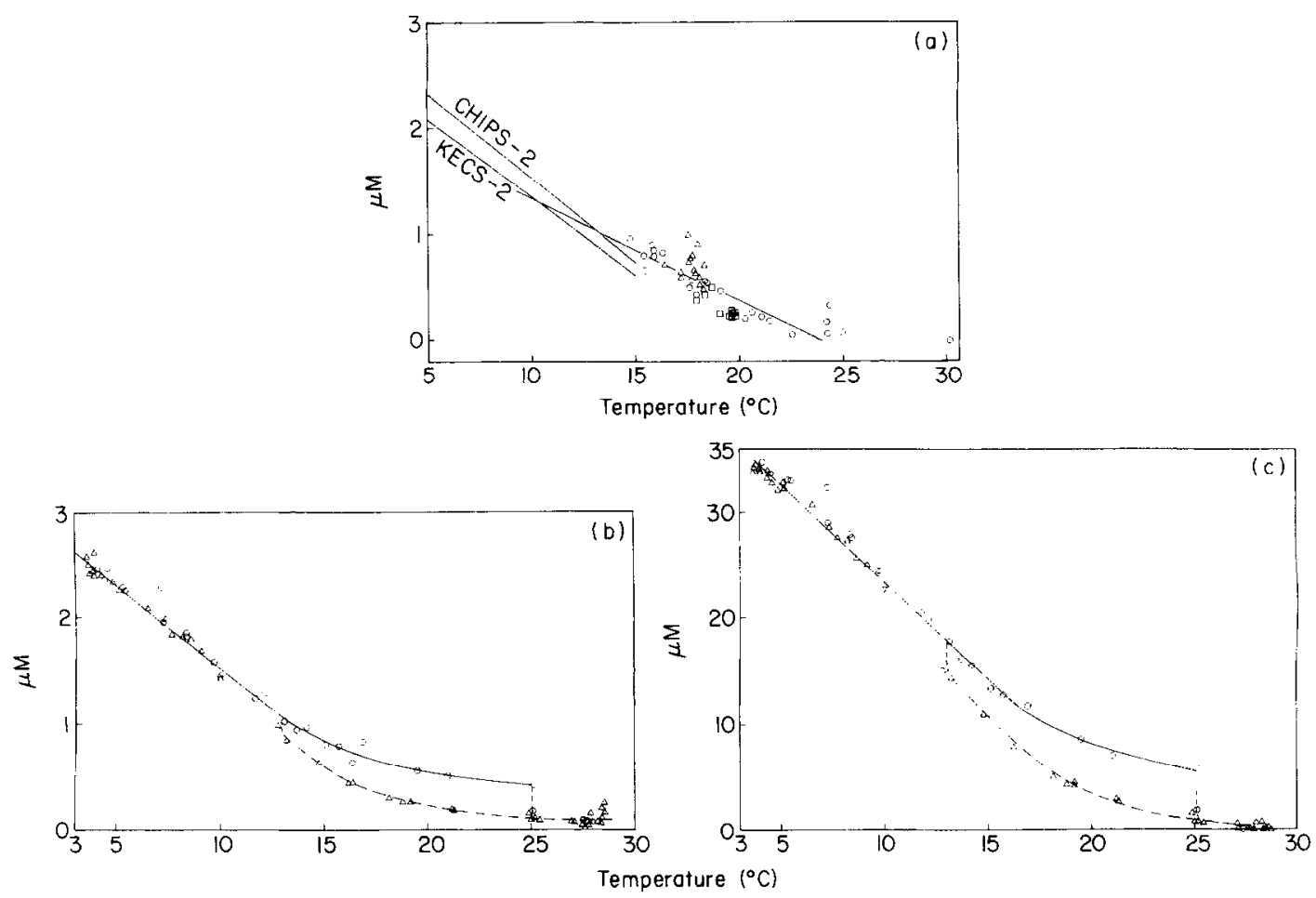

Figure 10. The relationship between (a) phosphate and temperature during spring 1987 $(-)$, stations 1 to $4 ; \Delta$, stations 5 to $7 ; \square$, stations 8 to 10 ), and (b) phosphate, (c) nitrate and temperature during summer 1985 ( $)$, stations 7 to 8 ; $\angle$, stations 10 to 14 ).

$$
\begin{array}{ll}
{\left[\mathrm{PO}_{4}\right]=2.81( \pm 0.06)-0.146( \pm 0.008) T} & \text { and } r=-0.99 \\
{[\mathrm{Si}]=148( \pm 6)-11.5( \pm 0.8) T} & \text { and } r=-0.95
\end{array}
$$

If the point of intersection at $13^{\circ} \mathrm{C}$ represents the end-member of the upwelling deep water, it will have a salinity of $34.4 \mathrm{psu}$ and contain about $16 \mu \mathrm{M}$ of nitrate, $1 \mu \mathrm{M}$ of phosphate, $18 \mu \mathrm{M}$ of silicate and $160 \mu \mathrm{M}$ of oxygen. Some diluted form of this water makes its way onto the shelf where its nitrate and phosphate are stripped to undetectable levels and silicate is reduced to about $2 \mu \mathrm{M}$, and it may constitute a significant source of nutrients to the East China Sea.

The relationships between nitrate, phosphate and temperature during summer 1985 are shown in Figure 10. Between 13 and $25^{\circ} \mathrm{C}$, the data points fell into two distinct groups: those from stations 7 and 8 at the inshelf sidc of the front and stations 10 to 14 at the offshelf side of the front that divided the Kuroshio water from the shelf waters. These abrupt changes reflect the lack of a transition zone between the shelf water and the Kuroshio water during this cruise. The data within this temperature range can be represented by concave curves or by two linear lines with a point of intersection at about $17 \mathrm{C}$. The former interpretation suggests that there was a removal, most likely a biological removal, of nutrients in these relatively warm and shallow waters. The latter interpretation would indicate mixing processes involving three end-members. The data from stations 10 to 14 showed more pronounced concavity above $13 \mathrm{C}$. At these stations, the thermocline and the nutriclines were considerably deeper than those at stations 7 and 8 . 
The removal of nutrients by biological processes might have been more important in controlling the concentrations of nutrients in these waters. Above $25 \mathrm{C}$, the concentrations of phosphate and nitrate were uniformly low, around the detection limit, in both groups of stations suggesting that biological removal of nutrients in the surface water was almost complete. Below about $13^{\circ} \mathrm{C}$, the relationships were identical at all stations, where,

$$
\begin{array}{ll}
{\left[\mathrm{NO}_{3}\right]=41.9( \pm 0.5)-1.85( \pm 0.08) T} & \text { and } r=-0.98 \\
{\left[\mathrm{PO}_{4}\right]=3.11( \pm 0.04)-0.158( \pm 0.005) T} & \text { and } r=-0.98
\end{array}
$$

The relationship between phosphate and temperature was almost identical to that observed during summer 1988. The nitrate-temperature relationship was slightly different. However, within the range of observed temperatures, the difference was probably insignificant relative to the uncertainties involved in this kind of analysis. Thus, the composition of the deep water in the Okinawa Trough does not seem to change perceptibly from season to season or from year to year.

During spring 1987 , only waters at temperatures above $15 \mathrm{C}$ were sampled. The relationship between phosphate and temperature (Figure 10) may be represented by the equation

$$
\left[\mathrm{PO}_{4}\right]=2 \cdot 3( \pm 0 \cdot 2)-0.096( \pm 0.009) T \quad \text { and } r=-0.82
$$

This line intersects the lines that represent the colder deep waters in the Okinawa Trough during summer 1985 and summer 1988 between 10 and $15^{\circ} \mathrm{C}$. This temperature at the point of intersection was similar to those observed during the other two cruises. Liu et al. (1989) examined the phosphate-temperature relationship during this cruise in greater detail. They observed that the relationship for the data points from stations 1 to 4 , the more offshelf stations, was significantly different from that for stations 5 to 10 . By treating stations 1 to 4 separately, they estimated that the end-member of the upwelling water had a temperature of $13.3^{\circ} \mathrm{C}$. The corresponding concentrations of nitrate and phosphate were 14.2 and $0.97 \mu \mathrm{M}$. These values are remarkably similar to those estimated here from the data from summer 1988. This similarity suggests that the temporal variations of the composition of the source of the upwelling water was probably small.

\section{Conclusions}

The boundary between the East China Sea and the Kuroshio water in the Okinawa Trough north-east of Taiwan was clearly defined by large contrasts in temperature and salinity across the frontal region at the sea surface. 'T he exact location of this boundary relative to the shelf break varies. During the periodical shelfward migration of the Kuroshio, it may get close enough to the shelf break to cause topographically induced upwelling onto the shelf, possibly in any season as observed in summer 1988 and spring 1987. At other times, such as during summer 1985, the Kuroshio can be far away from the shelf break. Under such circumstances, topographically induced upwelling onto the shelf might not have occurred, and, instead, filaments of shelf water could have spun out onto the Kuroshio. The observed chemical hydrography reflects the dynamic, and temporally and spatially variable nature of the mixing processes across the front.

The water at the core of the Kuroshio was nutrient-poor. The topographically induced upwelling water was modified Kuroshio water from about $300 \mathrm{~m}$ deep. Its composition seemed to remain rather constant with time with a temperature and salinity of around 
$13 \mathrm{C}$ and 34.4 psu respectively. It is enriched with nutrients, concentrations of nitrate, phosphate and silicate being 16,1 and $18 \mu \mathrm{M}$ respectively. The upwelling water can be identified as a pool of cold water at the vicinity of the shelf break. Depending on the intensity of the upwelling and the ability of organisms to strip off nutrients from surface waters, the upwelling water may or may not result in nutrient fronts at the sea surface. Such fronts were observed during spring 1987 and were not clearly evident during summer 1988.

The concentrations of the nutrients at temperatures above $13^{\circ} \mathrm{C}$ were linearly related to temperature during summer 1988 and spring 1987 when topographically induced upwelling occurred. As a result, it may be possible to estimate the exchange of nutrients between the East China Sea and the Kuroshio in the Okinawa Trough from the corresponding heat exchanges.

The deep water (below about $300 \mathrm{~m}$ ) in the Okinawa Trough at temperatures below $15 \mathrm{C}$ did not participate in cross-shelf mixing. Its chemical characteristics were significantly different from those of the deep water at comparable depths in the Philippine Sea.

\section{Acknowledgements}

The work was supported by the National Science Council through research grant NSC77-0209-M002a-15 to G. T. F. Wong and S.-C. Pai, NSC78-0209-M002a-11 to S.-C. Pai, NSC79-0209-M002a-09 to C.-T. Liu and NSC78-0209-M110-08 to C.-T. A. Chen. G. T. F. Wong was also supported by the National Science Council and the National Taiwan University as a Visiting Professor at the Institute of Oceanography of that University and by the Old Dominion University as a faculty on leave from its Department of Oceanography. We thank T. S. Fang, J. T. Yeh, G. C. Gong, C. C. Yang, C. C. Hung, L. Liu, W. C. Chen, J. S. Lin and the captain and crew of the R/V Ocean Researcher $I$ for their assistance during the cruises, and $W$. S. Chuang for many informative discussions on the oceanography in the study area.

\section{References}

Atkinson, L. P. 1985 Hydrography and nutrients of the southeastern U. S. continental shelf. In Oceanography of the Southeastern U.S. Continental Shelf (Atkinson, L. P., Menzel, D. W. \& Bush K. A., eds). American Geophysical Union, Washington, D.C., pp. 77-92.

Atkinson, L. P. \& Menzel, D. W. 1985 Introduction: oceanography of the southeast United States continental shelf. In Oceanography of the Southeastern U. S. Continental Shelf (Atkinson, L. P., Menzel, D. W. \& Bush, K. A., eds). American Geophysical Union, Washington, D.C., pp. 1-9.

Atkinson, L. P., Pietrafesa, L. J. \& Hofmann, E. E. 1982 An evaluation of nutrient sources to Onslow Bay, North Carolina. Fournal of Marine Research 40, 679-699.

Atkinson, L. P., Lee, T. N., Blanton, J. O. \& Chandler, W. S. 1983 Climatology of the southeastern United States continental shelf waters. Fournal of Geophysical Research 88, 4705-4718.

Beardslev, R. C., Limburner, R., Yu, H. \& Cannon, G. A. 1985 Discharge of the Changiiang (Yangtze River into the East China Sea. Continental Shelf Research 4, 57-76.

Carpenter, J. M. 1965 The Chesapeake Bay Institute technique for the Winkler dissolved oxygen method. Limnology and Oceanography 10, 141-143.

Chu, T. Y. 1976 Study of the Kuroshio current between Taiwan and Ishigakijima. Acta Oceanographica Taizanica 6, 1-24.

Dunstan, W. M. \& Atkinson, L. P. 1976 Sources for new nitrogen for the South Atlantic Bight. In Estuarinu Processe's, Uses, Stresses and Adaptation to the Estuary, Vol. 1 (Wiley, M., ed.). Academic Press, Orlando, Florida, pp. 69-78.

Edmond, J. M., Spivack, A., Grant, B. C., Hu, M.-H., Chen, Z., Chen, S. \& Zeng, X. 1985 Chemical dymamics of the Changiiang estuary. Continental Shelf Research 4, 17-36. 
Fan, K.-L. 1980 On upwelling off northeastern shore of Taiwan. Acta Oceanographica Taiwanica 11, $105-117$.

Fanning, K. A. \& Pilson, M. E. Q. 1973 On the spectrophotometric determination of dissolved silica in natural waters. Analytical Chemistry 45, 136-141.

Guan, B. 1983 A sketch of the current structure and eddy characteristics in the East China Sea. In Sedimentation on the Continental Shelf, with Special Reference to the East China Sea. China Ocean Press, Beijing, pp. 52-73.

Lee, T. N. \& Atkinson, L. P. 1983 Low-frequency current and temperature variability from Gulf Stream frontal eddies and atmospheric forcing along the southeast U. S. outer continental shelf. fournal of Geophysical Rescarch 88, 45414567.

Lee, T. N., Atkinson, L. P. \& Legeckis, R. 1981 Observations of a Gulf Stream frontal eddy on the Georgia continental shelf, April 1977. Deep Sea Research 28A, 347-378.

Liu, C.-T. 1983 As the Kuroshio turns: (I) characteristics of the current. Acta Oceanographica Taiwanica 14, $88-95$.

Liu, C.-T. \& Pai, S.-C. 1987 As Kuroshio turns: (II) the oceanic front north of Taiwan. Acta Oceanographica Taiwanica 18, 49-61.

Liu, C.-T., Pai, S.-C., Liau, S.-G. \& Liu, K.-K. 1987 a Data report of the first cruise $(1985 / 5)$ of the Cooperative Hydrographic Investigation of the Philippine Sea (CHIPS-1). Special Publication No. 50. Institute of Oceanography, National Taiwan University, 118 pp.

Liu, C.-T., Liau, S.-G., Pai, S.-C. \& Liu, K.-K. 19876 Water masses in western Philippine Sea-physical aspects. Acta Oceanographica Taiwanica 17, 1-17.

Liu, K.-K., Pai, S.-C. \& Liu, C.-T. 1989 Temperature-nutrient relationships in the Kuroshio and adjacent waters near Taiwan. Acta Oceanographica Taiwanica 21, 1-17.

Masuzawa, J. 1972 Water characteristics of the North Pacific central region. In Kuroshio (Stommel, H. \& Yoshida, K., eds). University of Washington Press, Seattle, WA, pp. 129-164.

Mogi, A. 1972 Bathymetry of the Kuroshio region. In Kuroshio (Stommel, H. \& Yoshida, K. eds). University of Washington Press, Seattle, WA, pp. 53-80.

Moore, W. S., Sarmiento, J. L. \& Key, R. M. 1986 Tracing the Amazon component of surface Atlantic water using ${ }^{128} \mathrm{Ra}$, salinity and silica. Fournal of Geophysical Research 91, 2574-2580.

Murphy, J. \& Riley, J. P. 1962 A modified single solution method for the determination of phosphate in natural waters. Analytica Chimica Acta 27, 31-36.

Nitani, H. 1972 Beginning of the Kuroshio. In Kuroshio (Stommel, H. \& Yoshida, K., eds). University of Washington Press, Seattle, WA, pp. 95-128.

Pai, S.-C., Liu, C.-J., Wen, L.-S., Lai, R.-L., Fang, T.-S., Jiann, K.-T. \& Yang, C.-C. 1987 Primary investigation of the Western Philippine Sea water-chemical data from the CHIPS-1 Expedition. Science and Technology foumal 21, 49-68.

Strickland, J. D. H. \& Parsons, T. R. 1972 A Practical Handbook of Seawater Analysis. Fisheries Research Board of Canada, Ottawa, Canada, $310 \mathrm{pp}$.

Wong, G. T. F. 1988 Alkalinity in the south-eastern United States continental shelf waters. Estuarine, Coastal and Shelf Science 27, 567-579.

Wong, G. T. F., Pai, S.-C. \& Chen, C.-T. A. 1989 chemical hydrography across the East China Sea-Kuroshio frontal region north-east of Taiwan. Acta Oceanographica Taiwanica 23, 1-18.

Yamamoto, G. \& Horikoshi, H. 1979 Preliminary report of the Hakuho Maru cruise KH-74-3 July 19August 22, 1974. The seas around Kuroshio area. Ocean Research Institute, University of Tokyo, $74 \mathrm{pp}$.

Yin, F. 1973 Preliminary study of cold water mass near N. N. E. of Taiwan. Acta Oceanographica Taiwanica 3, $157-180$. 